\title{
A socio-ecological landscape analysis of human-wildlife conflict in northern Botswana
}

\author{
Jeffrey A. Dunnink, Robyn Hartley, Lucas Rutina \\ JoAna Alves and Aldina M. A. Franco
}

\begin{abstract}
Human-wildlife conflict is one of the most pressing issues in conservation. Low-income rural communities are disproportionately affected by negative interactions with large predators, which often leads to retaliatory killings and persecution of the animals. To overcome this, socio-ecological studies that merge existing knowledge of large predator ecology with long-term livestock depredation monitoring are required. We examined patterns and drivers of livestock depredation in northern Botswana, using a mixed effects model of the government's long-term monitoring data on human-wildlife conflict, to identify ways to reduce depredation at key spatial and temporal scales. We compared the results to farmers' understanding of their personal risk within the landscape. We analysed 342 depredation events that occurred during 2008-2016, using variables measured at different scales. The variables affecting the locations of depredation events at the 2-km scale were distance to protected areas and predator and herbivore density, with increased depredation in the wet season. At a 1-km scale, herbivore density did not have a significant effect, but the effect of other variables was unchanged. The $4-\mathrm{km}$ scale model was influenced by livestock and herbivore density, with increased depredation in the wet season. Livestock depredation could be reduced by establishing an $8-\mathrm{km}$ livestock-free buffer along the protected area boundary. There was disparity between government data on human-wildlife conflict, depredation reported by farmers in interviews and farmers' risk awareness. Farmers would benefit from workshops providing tools to make evidence-based decisions and minimize their risk of negative interactions with wildlife. This would ultimately contribute to wildlife conservation in the Kavango-Zambezi Transfrontier Conservation Area.
\end{abstract}

JefFrey A. Dunnink* (Corresponding author) and Aldina M. A. Franco School of Environmental Sciences, University of East Anglia, Norwich Research Park, Norwich NR4 7TJ, UK. E-mail jeffdunnink@gmail.com

Robyn Hartley Wildlife ACT, Maun, Botswana

LuCAS Rutina $\dagger$ Okavango Research Institute, University of Botswana, Maun, Botswana

Joana Alves Centre for Functional Ecology, Department of Life Sciences, University of Coimbra, Coimbra, Portugal

*Present address: African Wildlife Foundation, Nairobi, Kenya $\dagger$ Also at: Ecosystem Conservation Foundation, Maun, Botswana

Received 28 May 2018. Revision requested 17 August 2018.

Accepted 8 November 2018. First published online 2 July 2019.
Keywords Botswana, human-wildlife conflict, landscape ecology, large African predators, livestock depredation, risk awareness, socio-ecology

\section{Introduction}

T uman-wildlife conflict is of global conservation 1 concern (Gusset et al., 2009; Seoraj-Pillai \& Pillay 2017). In the form of crop use by herbivores or livestock depredation by carnivores it results in substantial damage to both wildlife assemblages and the livelihoods of human communities living near them (Mbaiwa, 2005; Schiess-Meier et al., 2007; Hemson et al., 2009; Seoraj-Pillai \& Pillay 2017). Livestock depredation alone threatens up to $18 \%$ of sub-Saharan African households, costing up to $50 \%$ of their per capita income and preventing their emancipation from poverty (Kissui, 2008; Loveridge et al., 2017).

The retaliatory killing of apex predators limits the ecosystem resilience and functioning promoted by these keystone species (Ripple et al., 2014; Loveridge et al., 2017). In some areas such as East Africa, indiscriminate killing is the greatest threat to lion Panthera leo populations (IUCN, 2014). Persecution by farmers has driven the Falklands wolf Dusicyon australis and Tasmanian tiger Thylacinus cynocephalus to extinction and is a key threat to $85 \%$ of extant large carnivores globally (Woodroffe, 2000; Suryawanshi et al., 2017). Although they are legally protected, almost all large sub-Saharan African predators are threatened because of historical range shifts and population declines (Ripple et al., 2014). The lion, cheetah Acinonyx jubatus and leopard Panthera pardus are categorized as Vulnerable on the IUCN Red List (IUCN, 2017), the wild dog Lycaon pictus is Endangered and the spotted hyaena Crocuta crocuta faces severe persecution on agricultural land (IUCN, 2017; Loveridge et al., 2017).

Numerous strategies are available to reduce the impact of depredation on human livelihoods and wildlife populations, including compensation schemes, problem animal removal, improved livestock husbandry and wildlife monitoring (Gusset et al., 2009; Hemson et al., 2009; Hazzah et al., 2014; Seoraj-Pillai \& Pillay 2017). These interventions, however, are often financially unsustainable or occur post-conflict. Adopting a landscape ecological approach to identify important conflict drivers and patterns, so that 
preventive interventions at key spatial and temporal scales can be established, may provide a more sustainable solution (Treves et al., 2004; Valeix et al., 2012; Loveridge et al., 2017). This requires merging existing knowledge of the spatial and behavioural ecology of large predators with long-term depredation monitoring (Loveridge et al., 2017). Known landscape variables influencing livestock kill sites include season, distance from a protected area, local habitat type and herbivore and predator density of the surrounding area (Gusset et al., 2009; Inskip \& Zimmermann 2009; Davidson et al., 2012; Valeix et al., 2012; Suryawanshi et al., 2017). Scale also influences predator habitat selection in response to environmental characteristics, specifically the allocation of time budgets to areas within a territory (third order habitat selection; Johnson, 1980) and kill site selection (fourth order habitat selection; Johnson, 1980). Different landscape features, then, may induce different behavioural responses at different scales.

So-called human-wildlife conflict is often the physical expression of socio-political human-human conflict and is influenced by existing social systems (Matema \& Andersson 2015; Pooley et al., 2017). Conservation initiatives can be drawn into such conflicts by focusing on protecting animals as opposed to human settlements (Pooley et al., 2017). Any attempt to understand livestock depredation must, therefore, adopt a socio-ecological angle by identifying the interactions of livestock husbandry and ecological factors (Ogada et al., 2003; Hemson et al., 2009; Pooley et al., 2017). Community and individual risk awareness needs to be contrasted with robust depredation records to promote evidence-based decision making and potentially reduce depredation (Ogada et al., 2003; Hemson et al., 2009; Rutina et al., 2017).

However, long-term monitoring data on human-wildlife conflict are not available, limiting the capacity to identify effective threat reduction measures (Loveridge et al., 2017). In countries such as Botswana, where farmers receive compensation for livestock depredation, this can be overcome through investigations into the veracity of compensation claims (Schiess-Meier et al., 2007; Rutina et al., 2017). This study adopts a socio-ecological, landscape approach to examining livestock depredation, potentially contributing to the Kavango-Zambezi Trans-Frontier Conservation Areas' stated objective to mitigate humanwildlife conflict and promote the integration of conservation and human well-being (Loveridge et al., 2017; Rutina et al., 2017).

The primary objective is to determine the landscape ecological features influencing livestock depredation in northern Botswana. Secondly, we aim to determine which livestock husbandry practices best prevent depredation by large carnivores. The third objective is to evaluate farmers' awareness of livestock depredation risk.

\section{Study area}

The Chobe Enclave, northern Botswana (Fig. 1), has a mixed land-use pattern comprising agricultural land, human settlements and areas for wildlife management (Jones, 2002). This c. $2,000 \mathrm{~km}^{2}$ communal enclave is surrounded by protected areas to the south, east and west (Chobe National Park and Chobe Forest Reserve, IUCN category Ib and II, respectively) and the Namibian border (Chobe and Linyati Rivers) to the north. The area is considered semi-arid, receiving $650 \mathrm{~mm}$ mean annual rainfall, predominantly in the wet season (October-April; Schiess-Meier et al., 2007) and hosts wild herbivores such as Burchell's zebra Equus quagga, blue wildebeest Connohaetes taurinus, impala Aepyceros melampus and buffalo Syncerus caffer. The dominant economic activities are small-scale agro-pastoralism and employment in the civil service and tourism industries (Jones, 2002). The human population has been stable since 2002, with c. 7,500 people inhabiting the five main villages of Kachikau, Parakarungu, Kavimba, Satau and Mabele (Statistics Botswana, 2011). Cattle, the most common livestock, are kept in so-called cattle posts located throughout the enclave, grazed on communal land during the day and kept in enclosures called bomas overnight. Bomas are predominantly made from natural materials such as thorn shrubs and only occasionally incorporate modern fencing materials. Cattle are rarely raised commercially, but instead function as an investment and indicate wealth and social standing in a cultural sense (Jones, 2002; Mbaiwa, 2005).

\section{Methods}

\section{Density estimates}

We conducted a predator spoor survey using the sandy road network over 3 years (2014-2016). We drove along seven transects (mean length $16.2 \pm$ SD $0.65 \mathrm{~km}$; Fig. 1), representative of the dominant habitat types (short grass, forest and riverine) at a speed of c. $10 \mathrm{~km} / \mathrm{h}$ during the wet season (October-March) and dry season (June-September) of each year, covering a total of $777.5 \mathrm{~km}$. Only spoor from the previous 24 hours were counted, with transects never driven on consecutive days. Spoor found within $1 \mathrm{~km}$ of each other were considered to belong to the same animal unless otherwise identified by the tracker. Large predator spoor (lion, leopard, spotted hyaena, cheetah and wild dog) were identified by an expert tracker, to calculate predator density using the equation predator density $=$ track density/10o $\mathrm{km} \div 3.26$ following Funston et al. (2010) and Winterbach et al. (2016). We used ANOVAs to determine differences in predator density between seasons and habitat types.

We conducted prey counts separately from spoor surveys using line transects with distance sampling, focusing on 


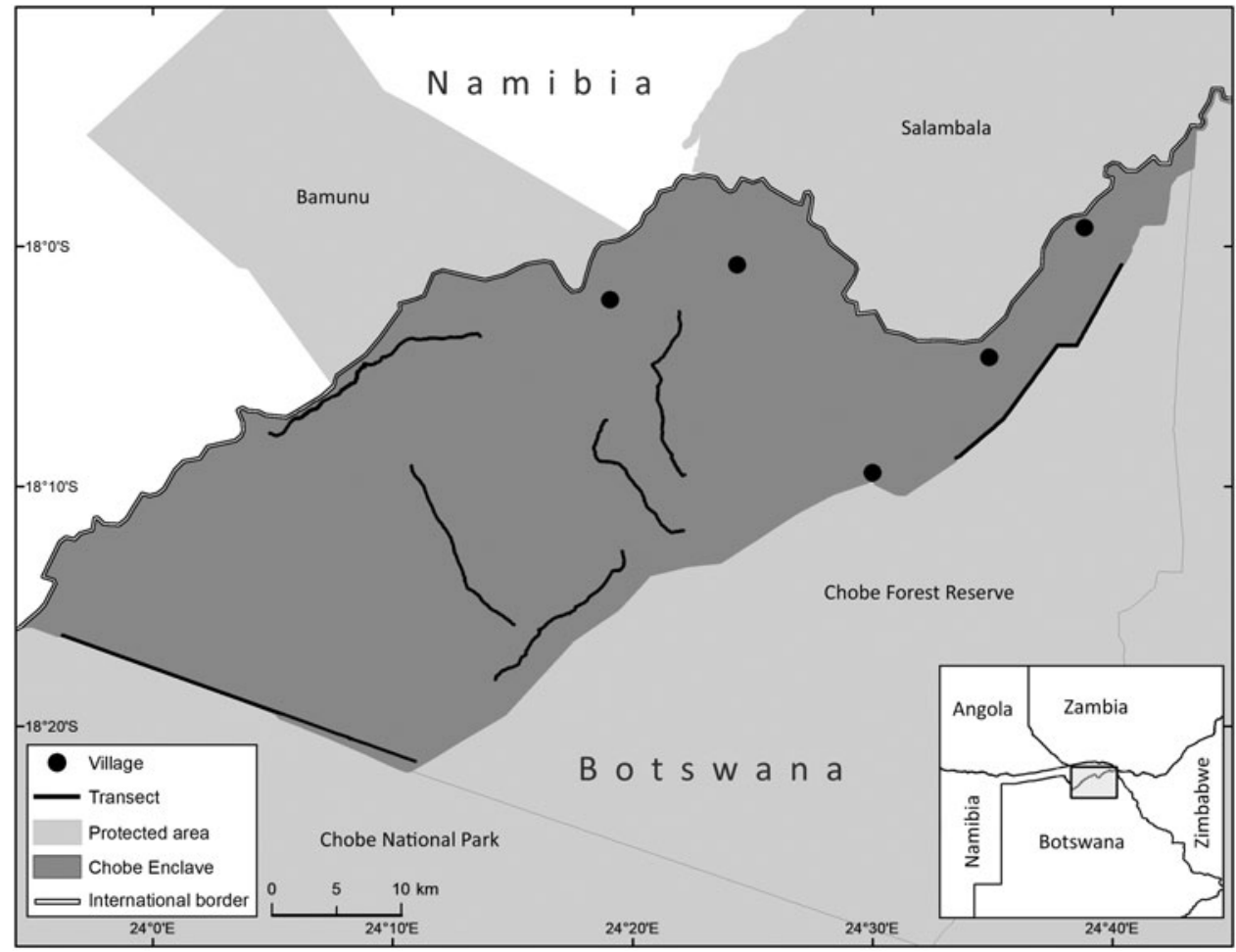

FIG. 1 Location of the Chobe Enclave, northern Botswana, including the five main villages and the location of transects used for predator spoor counts and prey density estimates. medium to large herbivores. For each encounter we recorded species, number of individuals, distance from the transect and position (the latter using a GPS). We drove along the same transects during the same time periods as for the spoor counts, at a speed of c. $20 \mathrm{~km} / \mathrm{h}$, covering a total of $933.4 \mathrm{~km}$ and counting animals within $400 \mathrm{~m}$ either side of the transect line. We estimated herbivore density in the wet and dry seasons using multiple covariate distance sampling in Distance 7.o (Thomas et al., 2010). Herbivore species, year and habitat were included in the detection probability model as covariates. We estimated herbivore density globally and per stratum (post-stratified by habitat). Model selection was based on the smallest Akaike information criteria (AIC) and variance and tested with $\chi^{2}$ goodness-of-fit (Buckland et al., 1993). We used a $\chi^{2}$ analysis to determine differences in the spatial (habitat) and temporal (season) distribution of herbivores.

\section{Landscape ecological variables}

The locations of livestock depredation incidents have been compiled in the problem animal control registry since 2008, by the Department of Wildlife and National Parks (DWNP). Records include location of the cattle post attacked (but not the location of the attack site), date, season, number of livestock killed and predator species. Attacks by hyaenas are often not recorded because they are not compensated for; we therefore excluded them from this analysis
(Schiess-Meier et al., 2007; Gusset et al., 2009; Loveridge et al., 2017).

Distance of each cattle post to the nearest protected area boundary was calculated in ArcMap 10.3 (ESRI, 2011) using the global network of protected areas (Gusset et al., 2009; UNEP-WCMC, 2016). Analyses of lion habitat selection have shown that kill sites are often located in densely vegetated habitats and within $2 \mathrm{~km}$ of a water hole in semi-arid areas similar to the study site (Valeix et al., 2010; Davidson et al., 2012, 2013). We calculated dominant habitat type surrounding each cattle post and distance to the nearest wet flood plain using previously generated habitat maps (Sianga \& Fynn, 2017) and determined mean annual rainfall in ArcMap 10.3 at a 30-arc second spatial resolution following Hijmans et al. (2005). Season was included because predators in semi-arid environments commonly select wild prey when they are more abundant during the wet season, and livestock during the dry season (Valeix et al., 2012; Davidson et al., 2013).

\section{Social methodology}

We administered 103 questionnaires to respondents evenly sampled across the five main villages of the Enclave during June-October 2014, with shorter follow-up questionnaires administered to 84 respondents during June-August 2016. Questionnaire design followed the British Sociological Association's ethical guidelines. Questionnaires were translated to Tswana and administered in person, at each cattle 
post, to participants $\geq 18$ years of age selected by chance encounter. Respondents were asked to divulge number of livestock owned, husbandry techniques used, number of depredation incidents over the preceding 12 months and household demographic data. We also asked respondents about their awareness of their personal risk of livestock depredation relative to other areas of the Enclave.

\section{Statistical analysis}

We conducted all statistical analyses in $R$ (R Core Team, 2016) and developed a repeated measure mixed effects logistic regression model using data from the problem animal control registry. The dependent variable was the location of cattle posts attacked by large predators. We coded each incident as binary, indicating whether a cattle post was attacked in each season of each year during 2008-2016 (excluding 2014 because of a lack of data). Independent variables were distance of cattle post to protected area, distance to flood plains, mean annual rainfall at each cattle post, dominant local habitat type and diversity, livestock and human populations in the area, surrounding herbivore and predator density, and season of attack. We analysed explanatory variables for collinearity prior to model selection. Habitat type and human density were removed as they were collinear with herbivore and livestock density, respectively. Random effects were year of attack and cattle post location. We removed $20 \%$ of the data randomly, to test the predictive strength of the final model by calculating the area under the curve of the receiver operating characteristics with a threshold of 0.7 (Brooker et al., 2002).

Predator, herbivore and livestock density, and mean annual rainfall were calculated within $2 \mathrm{~km}$ of each cattle post, based on the demonstrated influence of scale on lion foraging in similar systems (Valeix et al., 2010; Davidson et al., 2012). We repeated the modelling procedure using $1-\mathrm{km}$ and $4-\mathrm{km}$ buffers to determine the influence of scale. We also replaced predator density with lion, leopard and hyaena density and reran models independently.

We developed a general linear model to determine the influence of livestock husbandry and household demographics on depredation recorded in interviews. With the exception of active herding, all husbandry techniques (boma, fire at the boma and presence of boreholes supplying water to livestock) were visually inspected by interviewers. Demographic variables included the respondents' age and level of education, and number of people living in the household.

\section{Results}

Predator density (lions, leopards, hyaenas, cheetahs and wild dogs combined) was stable across seasons (dry:
$2.98 \pm$ SE 0.47 predators $/ 100 \mathrm{~km}^{2}$, wet: $2.61 \pm \mathrm{SE} 0.62$ predators $/ 100 \mathrm{~km}^{2}, F=0.22, \mathrm{df}=1, \mathrm{P}=0.64$ ) and between habitats (forest: $2.27 \pm \mathrm{SE} 0.73$ predators/100 $\mathrm{km}^{2}$, riverine: $2.1 \pm \mathrm{SE}$ 0.68 predators $/ 100 \mathrm{~km}^{2}$, short grass: $3.31 \pm \mathrm{SE} 0.52$ predators $\left./ 100 \mathrm{~km}^{2} ; F=1.14, \mathrm{df}=2, \mathrm{P}=0.32\right)$. There were, however, significantly more hyaenas $\left(11.5 \pm \mathrm{SE} 1.11\right.$ hyaenas $\left./ 100 \mathrm{~km}^{2}\right)$ than lions $\left(1.4 \pm \mathrm{SE} 0.41\right.$ lions $/ 100 \mathrm{~km}^{2}, \mathrm{~F}=73.71, \mathrm{df}=2$, $\mathrm{P}<0.001$ ) and leopards (o.8 \pm SE 0.24 leopards $/ 100 \mathrm{~km}^{2}$, $\mathrm{F}=73.71, \quad \mathrm{df}=2, \quad \mathrm{P}<0.001)$. Limited observations of cheetah and wild dog made comparisons with these species unreliable.

Herbivore density increased significantly in the wet (39.1 \pm SE 6.4 herbivores $\left./ \mathrm{km}^{2}\right)$ compared to the dry (13.3 \pm SE 2.5 herbivores $\left./ \mathrm{km}^{2}\right)$ season $\left(\chi^{2}=6.76, \mathrm{df}=1, \mathrm{P}=0.009\right)$. Both the short grass $\left(33.8 \pm \mathrm{SE} 4.5\right.$ herbivores $/ \mathrm{km}^{2} ; \chi^{2}=7.10, \mathrm{df}=$ $1, \mathrm{P}=0.007)$ and riverine habitats (26.6 \pm SE 9.3 herbivores/ $\mathrm{km}^{2} ; \chi^{2}=4.08, \mathrm{df}=1, \mathrm{P}=0.04$ ) held significantly higher herbivore density than the forest habitat $(9.9 \pm$ SE 3.5 herbivores $/ \mathrm{km}^{2}$ ) across all seasons. Zebras occurred at the highest density (12.75 \pm SE 2.42 individuals $/ \mathrm{km}^{2}$ ), whereas kudu occurred at $0.4 \pm$ SE 0.11 individuals $/ \mathrm{km}^{2}$ across all seasons.

Using a total of 342 livestock depredation incidents across 22 cattle posts recorded by the DWNP, the repeated measures mixed model found distance from the protected area (Fig. 2a), herbivore density (Fig. 2c) and predator density (Fig. 2d) to be significant negative predictors of livestock depredation. Depredation also significantly increased during the wet season (Fig. 2b). The interaction between distance to protected area and predator density indicated that depredation increased in close proximity to a protected area even where predator density was low (Table 1).

Model validation returned an area under the curve of 0.751 , indicating good performance. When considering individual predator models, as opposed to an agglomeration of all predators, only lion (coefficient $=-12.64 \pm$ SE 4.69, $z=-2.70, \quad \mathrm{P}=0.003 ;$ Fig. $3 \mathrm{a})$ and leopard density (coefficient $=1.31 \pm \mathrm{SE} 0.36, z=3.59, \mathrm{P}<0.0003$; Fig. $3 \mathrm{~b}$ ) significantly influenced livestock depredation.

Scale significantly influenced the results obtained. Similar to the $2-\mathrm{km}$ scale model, significant variables at the $1-\mathrm{km}$ scale included distance to protected area, predator density, season and the interaction between predator density and distance to the protected area. At the $4-\mathrm{km}$ scale significant variables included season and livestock and herbivore density (Table 1).

None of the reported livestock husbandry techniques significantly influenced livestock depredation (boma: $F=0.28$, $\mathrm{df}=1, \quad \mathrm{P}=0.59 ;$ fire: $F=0.44, \mathrm{df}=1, \mathrm{P}=0.51$; herder: $F=0.02, \quad \mathrm{df}=1, \quad \mathrm{P}=0.89 ; \quad$ borehole: $\quad F=1.18, \quad \mathrm{df}=1$, $\mathrm{P}=0.28$ ). Sixty per cent of interview respondents reported no difference in depredation with changing proximity to the protected area, and $40 \%$ of respondents were unaware of seasonal differences in depredation. Eighty-one per cent of respondents claimed to report all depredation incidents 

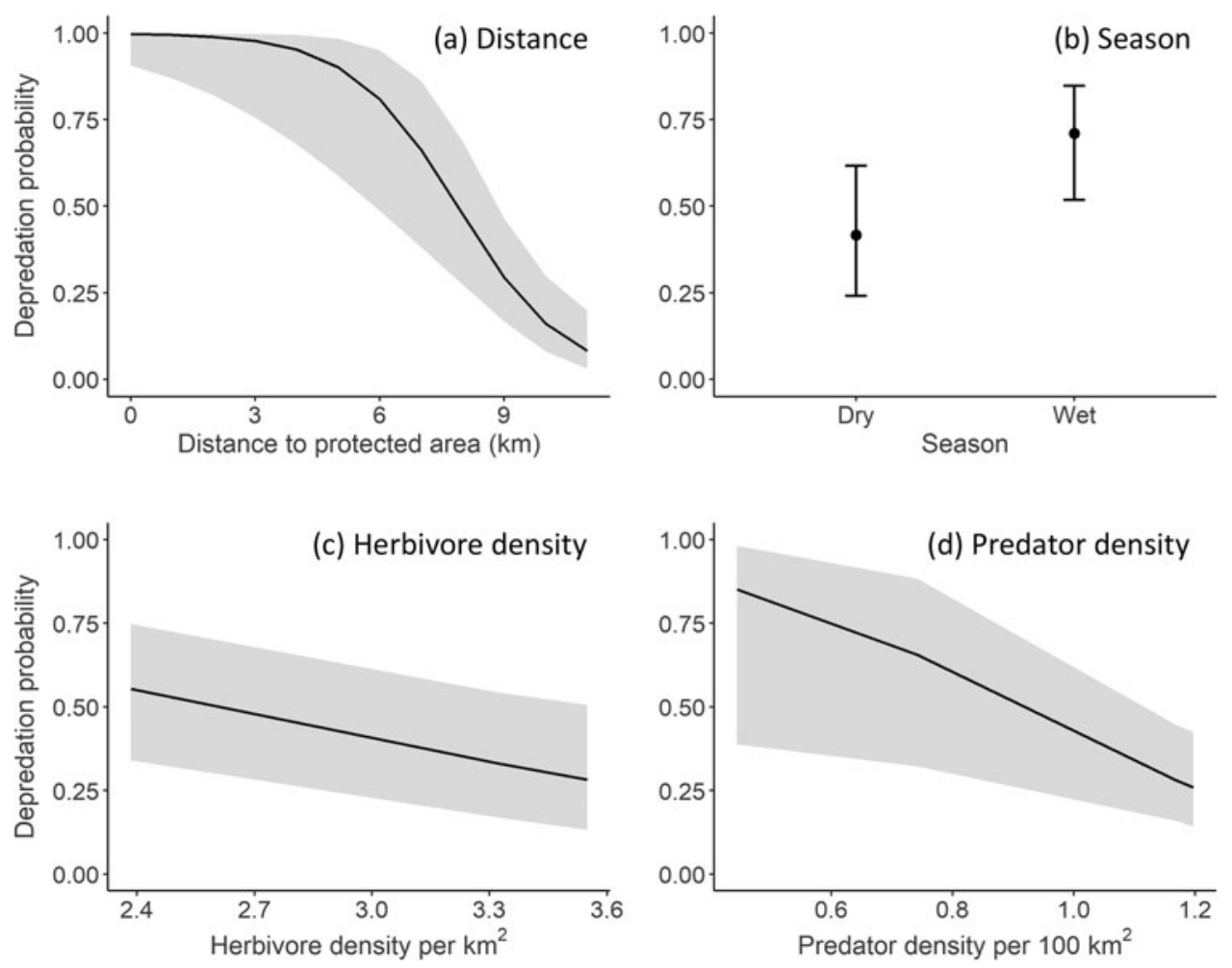

FIG. 2 Predicted probability of livestock depredation (a) with increasing distance to the protected area, (b) by season, (c) with herbivore density, and (d) with predator density.

TABLE 1 Livestock depredation models at 1-, 2- and 4-km scales, including the coefficient, standard error (SE), $z$-value and probability for all significant variables.

\begin{tabular}{lrrrc}
\hline Variable & Coefficient & \multicolumn{1}{l}{ SE } & \multicolumn{2}{c}{$z$} \\
\hline 1-km scale & & & & \\
Protected area distance & -4.31 & 1.23 & -3.51 & 0.0004 \\
Predator density & -31.61 & 9.54 & -3.31 & 0.0009 \\
Season of attack & 1.24 & 0.27 & 4.56 & $<0.0001$ \\
PredDens $\times$ PAdist & 3.47 & 1.06 & 3.27 & 0.001 \\
2-km scale & & & & \\
Protected area distance & -5.15 & 1.41 & -3.67 & 0.0002 \\
Predator density & -39.88 & 11.42 & -3.49 & 0.0004 \\
Herbivore density & -0.98 & 0.36 & -2.71 & 0.006 \\
Season of attack & 1.23 & 0.27 & 4.54 & $<0.0001$ \\
PredDens $\times$ PAdist & 4.35 & 1.21 & 3.59 & 0.0003 \\
4-km scale & & & & \\
Herbivore density & -0.93 & 0.43 & -2.14 & 0.03 \\
Season of attack & 1.24 & 0.27 & 4.57 & $<0.0001$ \\
Livestock density & 0.40 & 0.15 & 2.28 & 0.02 \\
\hline
\end{tabular}

${ }^{*}$ PredDens $\times$ PAdist, interaction between predator density and distance to the protected area.

to the DWNP and $35 \%$ claimed the DWNP response time was 24 hours-2 weeks. Nine per cent claimed the Department did not respond at all to reported incidents (Table 2). Hyaenas were reported by $35 \%$ of farmers as the most common predator in their area, followed by lions $(28 \%$ of respondents) and leopards (14\% of respondents).

The mean number of cattle per cattle post is 52, with a mean annual depredation of 52 livestock (range 27-103;
DWNP data) across the Enclave. Interviews captured significantly more depredation (293 cattle) than DWNP data (52 animals; $\chi^{2}$ : 95.9, $\mathrm{P}<0.001$; Fig. 4), and significantly more lion depredation (160 cattle) than DWNP data (44 animals; $\chi^{2}: 35.9, \mathrm{P}<0.001$ ) during 2015-2016. In total, the DWNP recorded 280 cattle, 54 goats and 8 donkeys (342 animals combined) depredated during 2008-2016, whereas interview respondents claimed a total of 616 cattle were lost to depredation during 2013-2016.

\section{Discussion}

The Chobe Enclave experiences a slightly higher rate of depredation ( $0.7 \%$ of available cattle in 2016) compared to Kweneng community area, Botswana ( $0.34 \%$ of available cattle in 2002; Schiess-Meier et al., 2007). Depredation recorded in interviews, however, indicated that $1.5 \%$ of available cattle were depredated in 2016. For comparison, interviews indicated that $3.9 \%$ of available cattle were depredated in 2014, whereas 1.0 and $3.2 \%$ were lost to theft and disease, respectively. Interview records were inflated by depredation caused by hyaenas, not captured by the DWNP, but lions still accounted for significantly more depredation recorded in interviews than DWNP data. It is possible that the $81 \%$ of respondents that claimed to report all depredation to the DWNP provide inaccurate reports because of their inability to identify predators correctly from tracks at kill sites (Rutina et al., 2017). Additionally, depredation was 

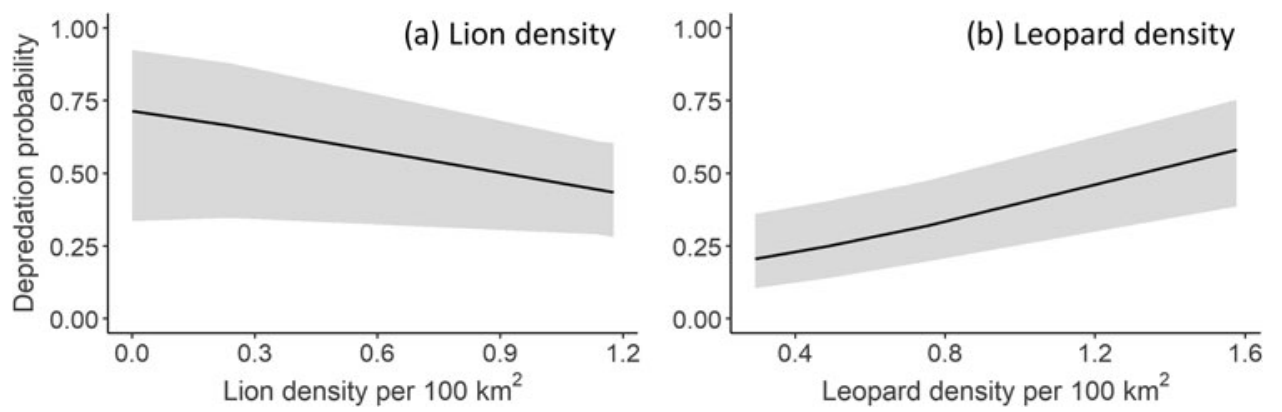

FIG. 3 Predicted probability of livestock depredation as a function of (a) lion density and (b) leopard density.

TABLE 2 Perception of livestock depredation risk in relation to distance from protected area and season, response time of the Department of Wildlife and National Parks (DWNP) to depredation reports, and actions taken after depredation, as reported in interviews with farmers in the Chobe Enclave, northern Botswana.

\begin{tabular}{|c|c|c|c|}
\hline Question & Response (\% of respondents) & & \\
\hline $\begin{array}{l}\text { Do most attacks occur close to }(\leq 1 \mathrm{~km}) \text { or farther from } \\
(>1 \mathrm{~km}) \text { the protected area? }\end{array}$ & Close to $(24)$ & Farther from (16) & No difference (60) \\
\hline Do most attacks occur in the wet or dry season? & Wet $(40)$ & Dry $(20)$ & No difference (40) \\
\hline $\begin{array}{l}\text { How long does it take DWNP to investigate reported } \\
\text { attacks? }\end{array}$ & 1 day (59) & 2 weeks (32) & $\begin{array}{l}\text { No response from } \\
\text { DWNP (9) }\end{array}$ \\
\hline Action taken after depredation & Reported to DWNP (81) & $\begin{array}{l}\text { Predator tracked } \\
\text { \& killed (4) }\end{array}$ & None (15) \\
\hline
\end{tabular}

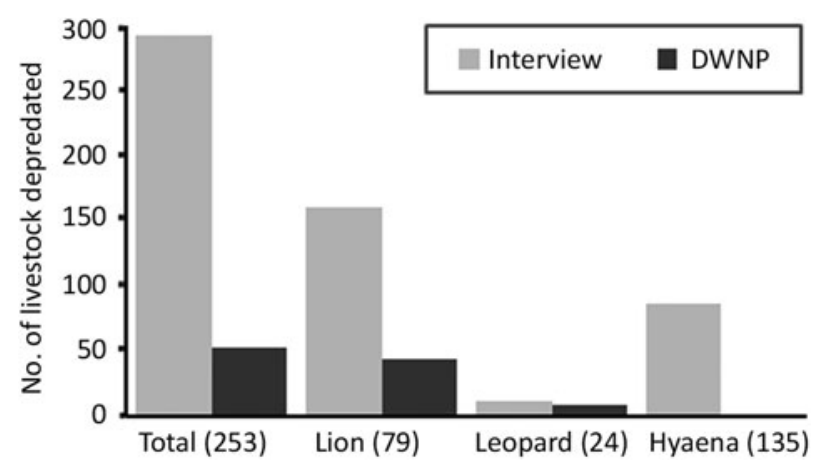

FIG. 4 Number of cattle lost to predators as reported by the Department of Wildlife and National Parks (DWNP) and by farmers directly in interviews for the years 2015 and 2016. The total number of farmers who reported each predator as most problematic in interviews is shown in parentheses.

possibly over-reported in interviews as respondents were asked to recall all incidents that occurred in the preceding year. The actual severity of livestock depredation probably falls between the DWNP and interview records.

Hyaenas occurred at the highest density of 11.5 individuals $/ 100 \mathrm{~km}^{2}$ and were reported to be the most common predator by $35 \%$ of respondents. In Ethiopian community areas, hyaenas can occur at 52 individuals $/ 100 \mathrm{~km}^{2}$ (Yirga et al., 2013). Although hyaenas were considered the most problematic predator, lions were responsible for the highest number of depredation events in interview and DWNP data. Lions occurred at the second highest density of 1.4 individuals $/ 100 \mathrm{~km}^{2}$, similar to that in grazing areas surrounding
Khutse Game Reserve (1.21 lions/100 km²; Bauer et al., 2014) and were reported to be the most common predator by $28 \%$ of respondents. Leopards occurred at the third highest density of 0.8 individuals $/ 100 \mathrm{~km}^{2}$, similar to community areas in South Africa (0.87 leopards $/ 100 \mathrm{~km}^{2}$; Balme et al., 2010) and were reported as the most common predator by $14 \%$ of respondents. Chobe Enclave farmers, therefore, are aware of predator abundance relative to other predators but their associations with each species are not solely based on depredation (Hazzah et al., 2017). Persecution of hyaenas in particular is probably caused by the combination of their relatively high density, lack of compensation for damage caused by them, and socio-cultural norms and fears associated with this species. Community perceptions and predator populations need to be actively managed in the Kavango-Zambezi Transfrontier Conservation Area to ensure community areas do not become ecological traps (Yirga et al., 2013; Rutina et al., 2017).

Lions exhibit hierarchical habitat selection (Johnson, 1980), spending most of their time in open acacia or short grass habitats (third order habitat selection), whereas kill site selection (fourth order habitat selection) occurs in dense thicket or forested habitats where prey can be caught more easily (Hopcraft et al., 2005; Davidson et al., 2012, 2013). This, coupled with the non-significant increase in predator density in the short grass habitat, could explain why increased predator density surrounding a cattle post decreased the probability of livestock depredation, contrary to Inskip \& Zimmermann (2009). Leopards, however, prefer the same habitat type for third- and fourth-order habitat 
selection (Balme et al., 2007), which explains why increased lion density decreased the probability of livestock depredation but increased leopard density increased the risk of depredation. There is an opportunity for human-predator coexistence as the presence of lions does not necessarily result in livestock depredation, but the presence of livestock in areas ecologically suitable for predatory behaviour does. Livestock husbandry areas should therefore be strategically placed away from thicket and forested habitats.

Husbandry systems should likewise be moved away from protected area boundaries as increased distance from a protected area decreased the probability of livestock depredation (Inskip \& Zimmermann 2009; Loveridge et al., 2017). However, $60 \%$ of interview respondents stated that livestock depredation is not influenced by proximity to a protected area. The interaction between distance from the protected area and predator density showed that the probability of depredation dramatically decreased beyond $8 \mathrm{~km}$ from the protected area boundary at low predator densities, but remained stable at high predator densities. Providing farmers with this information and encouraging a livestock free buffer zone around the protected area (recommended elsewhere; Beale et al., 2013) could reduce depredation and improve protected area management.

Contrary to previous studies (Ogada et al., 2003; Hemson et al., 2009), none of the reported husbandry techniques (herding, boma, fire at the boma and borehole present) significantly influenced livestock depredation in the Chobe Enclave. Bulte \& Rondeau (2005) hypothesized that compensation schemes reduce farmer vigilance, decreasing the impact of livestock husbandry. Fear of predators and the loss of Indigenous ecological knowledge amongst younger generations may also reduce farmer's capacity for effective depredation mitigation, especially if compensation is expected (Packer et al., 2011; Rutina et al., 2017). Respondents may have over-reported herding effort as interviewers were unable to confirm active herder presence. Additionally, only $6 \%$ of respondents used a so-called predator-proof boma supplied by the DWNP (2 m high steel and wire boma). Such predator-proof bomas should be supplied to farmers across the Enclave, in combination with training on effective depredation prevention (Hazzah et al., 2014; Lichtenfeld et al., 2015).

Herbivore density was highest in the short grass habitat and during the wet season because of increased forage quality and seasonal migrations of zebra and wildebeest from central regions of Botswana (Fynn et al., 2014). The management of livestock grazing systems to conserve functional landscape heterogeneity may allow for increased herbivore populations and a concomitant reduction in livestock depredation, as increased herbivore density decreased depredation probability (Fynn et al., 2014; Suryawanshi et al., 2017). This intervention must be closely monitored to ensure increasing herbivore populations do not increase predator abundance and, ultimately, livestock depredation (Suryawanshi et al., 2017).

Despite the increased herbivore density, and contrary to previous studies (Valeix et al., 2012; Davidson et al., 2013), livestock depredation increased during the wet season. One possibility is that lion spatial time allocation shifts seasonally, with prolonged presence in the Enclave during the wet season and in the protected area during the dry season. This is supported by Makgadikgadi lions altering their home range size and time allocation in response to wild herbivore migrations (Valeix et al., 2012). This would not change seasonal predator density but could increase depredation in the wet season. Only $40 \%$ of respondents were aware of this temporal change in risk, further highlighting the need for effective training in depredation prevention. Socio-ecological variables included in our model were assumed not to change when backcast from 2014-2016 to 2008, but it is possible (although unlikely given the stable human, predator and herbivore densities) that these variables did change, which could affect the results of this study.

The influence of scale is vital when considering habitat selection (Davidson et al., 2012). Prey make a priori assessments of risk based on surrounding landscape characteristics, whereas predators select habitat features at different scales to increase prey encounter rates and catchability (Davidson et al., 2012; Courbin et al., 2015). Predator density significantly influenced depredation at the $1-\mathrm{km}$ and $2-\mathrm{km}$ scales but not at the $4-\mathrm{km}$ scale. This indicates that $4 \mathrm{~km}$ is too large a scale to influence large predator third order habitat selection. Herbivore density significantly influenced depredation at the 2 -km scale (in accordance with lion habitat selection and restricted area foraging; Valeix et al., 2010; Davidson et al., 2012) and the 4-km scale, indicating the possibility of large predator fourth order habitat selection occurring at multiple scales. Livestock density significantly influenced depredation at the $4-\mathrm{km}$ scale, indicating the possibility of different prey types influencing kill-site selection at different scales. Further research is needed to test this.

If implemented, the recommendations presented here could potentially promote improved human-carnivore coexistence in the Chobe Enclave, contributing to the conservation management of the Kavango-Zambezi Transfrontier Conservation Area. Training in appropriate livestock husbandry techniques and promotion of Indigenous ecological knowledge could help farmers overcome fears of large predators, make evidence-based decisions and reduce the gap between perceived and actual depredation risk.

Acknowledgements The authors would like to thank the Department of Wildlife and National Parks, Government of Botswana, for their assistance and access to data. This project was partially funded by the European Commission through the Erasmus Mundus Master Course - International Master in Applied Ecology (FPA 2023-0224/532524-1-FR-2012-1-ERA MUNDUS-EMMC) and 
the Southern African Science Centre for Climate Change and Adaptive Land Management. JA was funded by European Social Fund and the Portuguese Operational Human Potential Program (POPH/FSE) from the Portuguese Foundation for Science and Technology through the fellowship SFRH/BPD/123087/2016.

Author contributions Data collection, analysis, and writing: JD; data collection: RH; distance analysis: JA; study design: LR; data analysis and discussion: AF.

\section{Conflict of interest None.}

Ethical standards This research abided by the Oryx guidelines on ethical standards.

\section{References}

Balme, G., Hunter, L. \& Slotow, R. (2007) Feeding habitat selection by hunting leopards Panthera pardus in a woodland savanna: prey catchability versus abundance. Animal Behavior, 74, 589-598.

Balme, G.A., Slotow, R. \& Hunter, L.T. (2010) Edge effects and the impact of non-protected areas in carnivore conservation: leopards in the Phinda-Mkhuze Complex, South Africa. Animal Conservation, 13, 315-323.

Bauer, D., Schiess-Meier, M., Mills, D.R. \& Gusset, M. (2014) Using spoor and prey counts to determine temporal and spatial variation in lion (Panthera leo) density. Canadian Journal of Zoology, 92, 97-104.

Beale, C.M., van Rensberg, S., Bond, W.J., Coughenour, M., Fynn, R., Gaylard, A. et al. (2013) Ten lessons for the conservation of African savannah ecosystems. Biological Conservation, 167, 224-232.

Brooker, S., Hay, S.I. \& BUndy, D.A.P. (2002) Tools from ecology: useful for evaluating risk models? Trends in Parasitology, 18, 70-74.

Buckland, S.T., Anderson, D.R., Burnham, K.P. \& LaAke, J.L. (1993) Distance Sampling: Estimation of Biological Populations. Chapman and Hall, London, UK.

Bulte, E.H. \& Rondeau, D. (2005) Why compensating wildlife damages may be bad for conservation. Journal of Wildlife Management, 69, 14-19.

Courbin, N., Loveridge, A.J., Macdonald, D.W., Fritz, H., Valeix, M., Makuwe, E.T. \& Chamaille-Jammes, S. (2015) Reactive responses of zebras to lion encounters shape their predator-prey space game at large spatial scale. Oikos, 125, 829-838.

Davidson, Z., Valeix, M., Loveridge, A.J., Hunt, J.E., Johnson, P.J., Madzikanda, H. \& Macdonald, D.W. (2012) Environmental determinants of habitat and kill site selection in a large carnivore: scale matters. Journal of Mammalogy, 93, 677-685.

Davidson, Z., Valeix, M., Van Kesteren, F., Loveridge, A.J., Hunt, J.E., Murindagomo, F. \& Macdonald, D.W. (2013) Seasonal diet and prey preference of the African lion in a waterhole-driven semi-arid savanna. PLOS ONE, 8, e55182.

ESRI (2011) ArcGIS Desktop: Release 10. Environmental Systems Research Institute, Redlands, USA.

Funston, P.J., Frank, L., Stephens, L., Davidson, Z., Loveridge, A.J., Macdonald, D.W. et al. (2010) Substrate and species constraints on the use of track incidences to estimate African large carnivore abundance. Zoology, 281, 56-65.

Fynn, R.W.S., Chase, M. \& Roder, A. (2014) Functional habitat heterogeneity and large herbivore seasonal habitat selection in northern Botswana. South African Journal of Wildlife Research, $44,1-15$.
Gusset, M., Swarner, M.J., Mponwane, L., Keletile, K. \& McNutt, J.W. (2009) Human-wildlife conflict in northern Botswana: livestock predation by Endangered African wild dog Lycaon pictus and other carnivores. Oryx, 43, 67-72.

Hazzah, L., Dolrenry, S., Naughton, L., Edwards, C.T., Mwebi, O., Kearney, F. \& Frank, L. (2014) Efficacy of two lion conservation programs in Maasailand, Kenya. Conservation Biology, $28,851-860$.

Hazzah, L., Bath, A., Dolreny, S., Dickman, A. \& Frank, L. (2017) From attitudes to actions: predictors of lion killing by Maasai warriors. PLOS ONE, 12, e0170796.

Hemson, G., Maclennan, S., Mills, G., Johnson, P. \& Macdonald, D. (2009) Community, lions, livestock and money: a spatial and social analysis of attitudes to wildlife and the conservation value of tourism in a human-carnivore conflict in Botswana. Biological Conservation, 142, 2718-2725.

Hijmans, R. J., Cameron, S.E., Parra, J.L., Jones, P.G. \& Jarvis, A. (2005) Very high resolution interpolated climate surfaces for global land areas. International Journal of Climatology, 25, 1965-1978.

Hopcraft, J.G.C., Sinclair, A.R.E. \& Packer, C. (2005) Planning for success: Serengeti lions seek prey accessibility rather than abundance. Journal of Animal Ecology, 74, 559-566.

Inskip, C. \& Zimmermann, A. (2009) Human-felid conflict: a review of the patterns and priorities worldwide. Oryx, 43, 18-34.

IUCN (2014) Regional Conservation Strategy for the Lion Panthera leo in Eastern and Southern Africa. IUCN, Gland, Switzerland.

IUCN (2017) The IUCN Red List of Threatened Species. Version 2017-3. Http://www.iucnredlist.org [accessed 22 April 2018].

Johnson, D.H. (1980) The comparison of usage and availability measurements for evaluating resource preference. Ecology, 75, 1397-1405.

Jones, B.T.B. (2002) Chobe Enclave, Botswana-Lessons Learnt from a CBNRM Project 1993-2002. IUCN/SNV CBNRM Support Programme, Gaborone, Botswana.

KIssuI, B.M. (2008) Livestock predation by lions, leopards, spotted hyenas, and their vulnerability to retaliatory killing in the Maasai steppe, Tanzania. Animal Conservation, 11, 422-432.

Lichtenfeld, L.L., Trout, C. \& Kismir, E.L. (2015) Evidence-based conservation: predator-proof bomas protect livestock and lions. Biodiversity and Conservation, 24, 483-491.

Loveridge, A.J., Kuiper, T., Parry, R.H., Sibanda, L., Hunt, J.H., StapelKamp, B. et al. (2017) Bells, bomas and beefsteak: complex patterns of human-predator conflict at the wildlife-agropastoral interface in Zimbabwe. PeerJ, 5, e2898.

Matema, S. \& Andersson, J.A. (2015) Why are lions killing us? Human-wildlife conflict and social discontent in Mbire District, northern Zimbabwe. Journal of Modern African Studies, 53, 93-120.

Mbaiwa, J.E. (2005) Wildlife resource utilisation at Moremi Game Reserve and Khwai community area in the Okavango Delta, Botswana. Environmental Management, 77, 144-156.

Ogada, M.O., Woodroffe, R., Oguge, N.O. \& Frank, L.G. (2003) Limiting depredation by African carnivores: the role of livestock husbandry. Conservation Biology, 17, 1521-1530.

Packer, C., Swanson, A., Ikanda, D. \& Kushnir, H. (2011) Fear of darkness, the full moon and the nocturnal ecology of African lions. PLOS ONE, 6, e22285.

Pooley, S., Barua, M., Beinart, W., Dickman, A., Holmes, G., Lorimer, J. et al.. (2017) An interdisciplinary review of current and future approaches to improving human-predator relations. Conservation Biology, 31, 513-523.

R Core Team (2016) R: A Language and Environment for Statistical Computing. R Foundation for Statistical Computing, Vienna, Austria. Http://www.R-project.org [accessed 12 March 2019]. 
Ripple, W.J., Estes, J.A., Beschta, R.L., Wilmers, C.C., Ritchie, E., Hebblewhite, M. et al. (2014) Status and ecological effects of the world's largest carnivores. Science, 343, 124-148.

Rutina, L.P., Mogwera, K.M., Seonyatseng, E., Mpofu, C. \& Ntloyathuto, D. (2017) 'Herders' ecological knowledge and carnivore predation on livestock investigations in Makgadikgadi and Nxai National Parks, Botswana. Koedoe, 59, 1-2.

Schiess-Meier, M., Ramsauer, S., Gabanapelo, T. \& Konig, B. (2007) Livestock predation-insights from problem animal control registers in Botswana. Journal of Wildlife Management, 71, 1267-1274.

Seoraj-Pillai, N. \& Pillay, N. (2017) A meta-analysis of humanwildlife conflict: South African and global perspectives. Sustainability, 9, 1-21.

SIANGA, K. \& FynN, R.W.S. (2017) The vegetation and wildlife habitats of the Savuti-Mababe-Linyati ecosystem, northern Botswana. Koedoe, 59, 1-16.

Statistics Botswana (2011) Botswana Population and Housing Census. Http://www.statsbots.org.bw/sites/default/files/2011\% 2oPopulation\%2oand\%2ohousing\%2oCensus.pdf [accessed 9 July 2017].

Suryawanshi, K.R., Redpath, M.R., Bhatnagar, Y.V., Ramakrishnan, U., Chaturvedi, V., Smout, S.C. \& Mishra, C. (2017) Impact of wild prey availability on livestock predation by snow leopards. Royal Society Open Science, 4, 170026.

Thomas, L., Buckland, S.T., Rexstad, E.A., LaAke, J.L., StringberG, S., Hedley, S.J. et al.. (2010) Distance software: design and analysis of distance sampling surveys for estimating population size. Journal of Applied Ecology, 47, 5-14.

Treves, A., Naughton-Treves, L., Harper, E.K., Mladenoff, D.J., Rose, R.A., Sickley, T.A. \& Wydeven, A.P. (2004) Predicting human-carnivore conflict: a spatial model derived from 25 years of data on wolf predation on livestock. Conservation Biology, 18, 114-125.

UNEP-WCMC (2016) World Database on Protected Areas User Manual 1.3. UNEP-WCMC, Cambridge, UK. Https://protectedplanet.net/ [accessed 1 February 2017].

Valeix, M., Loveridge, J., Davidson, Z., Madzikanda, H., Fritz, H. \& Macdonald, D. (2010) How key habitat features influence large terrestrial carnivore movements: waterholes and African lions in a semi-arid savanna of north-western Zimbabwe. Landscape Ecology, 25, 337-351.

Valeix, M., Hemson, G., Loveridge, A.J., Mills, G. \& Macdonald, D.W. (2012) Behavioural adjustments of a large carnivore to access secondary prey in a human-dominated landscape. Journal of Applied Ecology, 49, 73-81.

Winterbach, C.W., Ferreira, S.M., Funston, P.J. \& Somers, M.J. (2016) Simplified large African carnivore density estimators from track indices. PeerJ, 4, e2662.

Woodroffe, R. (200o) Predators and people: using human densities to interpret declines of large carnivores. Animal Conservation, 3, 165-173.

Yirga, G., Ersino, W., De Jongh, H., Leirs, H., Gebrehiwot, K., Deckers, J. \& BAuer, H. (2013) Spotted hyena (Crocuta crocuta) coexisting at high density with people in Wukro district, northern Ethiopia. Mammalian Biology, 78, 193-197. 